\section{International Scientific Journal Theoretical \& Applied Science}

\author{
p-ISSN: 2308-4944 (print) e-ISSN: 2409-0085 (online) \\ Year: $2015 \quad$ Issue: $06 \quad$ Volume: 26
}

Published: $30.06 .2015 \quad$ http://T-Science.org
Denis Alexandrovich Chemezov

Master of Engineering and Technology, Corresponding member of International Academy of

Theoretical and Applied Sciences, Lecturer of Vladimir Industrial College, Russia chemezov-da@yandex.ru

SECTION 7. Mechanics and machine construction.

\title{
ANALYSIS OF CRACK FORMATION IN TITANIUM ALLOY DURING EQUAL CHANNEL ANGULAR PRESSING
}

Abstract: The article presents the dependences of the formation of cracks in the pressing titanium alloy from the degree of deformation of the material.

Key words: equal channel angular pressing, deformation, crack.

Language: Russian

Citation: Chemezov DA (2015) ANALYSIS OF CRACK FORMATION IN TITANIUM ALLOY DURING EQUAL CHANNEL ANGULAR PRESSING. ISJ Theoretical \& Applied Science 06 (26): 20-23.

Soi: http://s-o-i.org/1.1/TAS*06(26)5 Doi: crossef http://dx.doi.org/10.15863/TAS.2015.06.26.5

\section{АНАЛИЗ ОБРАЗОВАНИЯ ТРЕЩИН В ТИТАНОВОМ СПЛАВЕ ПРИ РАВНОКАНАЛЬНОМ УГЛОВОМ ПРЕССОВАНИИ}

Аннотация: В статье представлены зависимости образования трещин в прессуемом титановом сплаве от степени деформации материала.

Ключевые слова: равноканальное угловое прессование, деформация, трещчна.

Трещина в металлах - экстремальный дефект, представляющий собой области с полностью и частично нарушенными межатомными связями [1]. Образование и последующее развитие трещин в сплошных металлических материалах подвергающихся холодному или горячему пластическому деформированию приводит к постепенному разрушению заготовки.

Деформационные трещины зарождаются в металлических материалах характеризующихся пониженной пластичностью при температурах деформации. Специфические методы интенсивного пластического деформирования металлических материалов имеют ряд особенностей возникновения трещин. При равноканальном угловом прессовании (РКУП) трещины в материале возникают из-за значительных усилий, действующих на заготовку, и незаполнения внешнего угла в матрице. Существенно влияет на интенсивность трещинообразования, в материалах прессуемых заготовок, конфигурация и ориентация приемного и выходного каналов матрицы.

Анализ механизма деформации заготовки методом РКУП, при помощи инструментов компьютерной программы LS-DYNA, позволит определить границы и тенденции образования трещин в материале.

В качестве материала заготовки, прессуемой в холодном состоянии под углом 90, принят титановый сплав ВТ8 обладающий следующими физико-механическими свойствами: $\rho=4520$ $\kappa г / \mathrm{M}^{3}, E=1 \times 10^{5} \mathrm{MПа,} \mu=0.36, \sigma_{T}=930 \mathrm{MПа} \mathrm{[2].}$ Усилие, действующее на заготовку наружным диаметром 25 мм и длиной 50 мм, составляло 50 МПа.

Расчет величин деформаций материала, при которых происходит образование трещин, производился суммарно для всего объема прессуемой заготовки. Для удобства расчета весь объем заготовки был разделен на следующие участки: 1 - материал, расположенный в приемном канале матрицы (давление на торцевую поверхность заготовки пуансона); 2 материал, расположенный в месте пересечения приемного и выходного каналов матрицы (прогнозирование интенсивного трещинообразования); 3 - материал, расположенный в выходном канале матрицы (постепенный переход материала в равновесную структуру, остаточные напряжения). 
Предварительно получены максимальные значения напряжений и деформаций материала на всем временном диапазоне РКУП. Главные напряжения ( $\sigma_{1}-$ первое, $\sigma_{2}-$ второе, $\sigma_{3}-$ третье) - нормальные напряжения, возникающие на главных площадках (площадки проходят через напряженные точки прессуемого материала) [3]. Максимальная величина напряжения материала наблюдается в месте пересечения каналов матрицы (граница внутреннего сопряжения поверхности заготовки и выходного канала) и равна $\sigma_{1}$ [4]. Значения $\sigma_{2}$ и $\sigma_{3}$ можно найти из $\sigma_{l}$ : $\sigma_{2}=0.51 \sigma_{1} ; \quad \sigma_{3}=-0.065 \sigma_{1}$. Пластическая

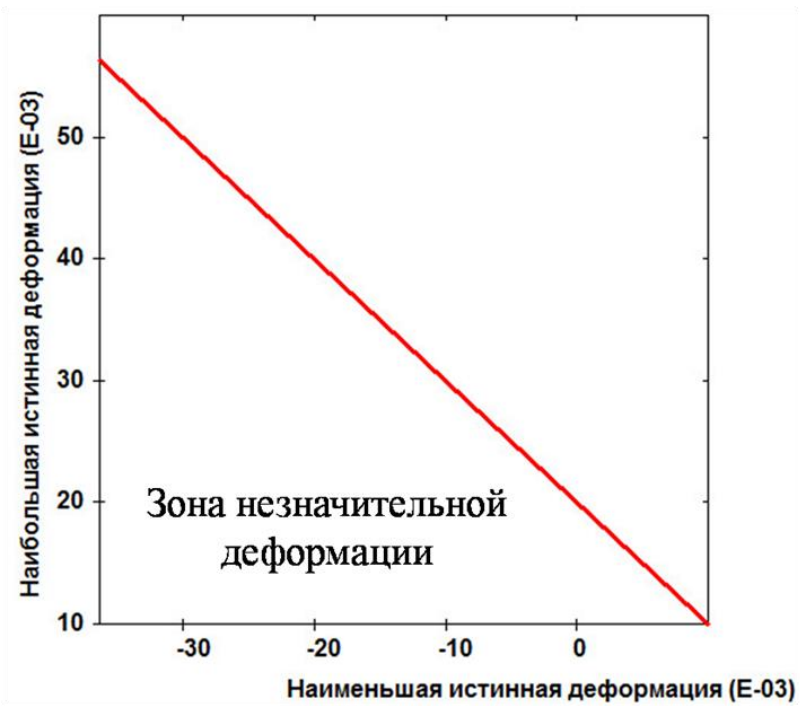

a) деформация заготовки составляла от 0,21 до 0,98 на момент половины продавленного объема материала в выходной канал матрицы.

Результаты исследования представлены в виде диаграмм, на которых отображены зоны интенсивности деформаций материала (рис. 1) и зоны образования трещин в материале от истинных деформаций (рис. 2) при РКУП. На диаграммах истинная деформация есть отношение изменения в размерах нагруженной заготовки к ее размерам до приложения нагрузки $[5,6]$.

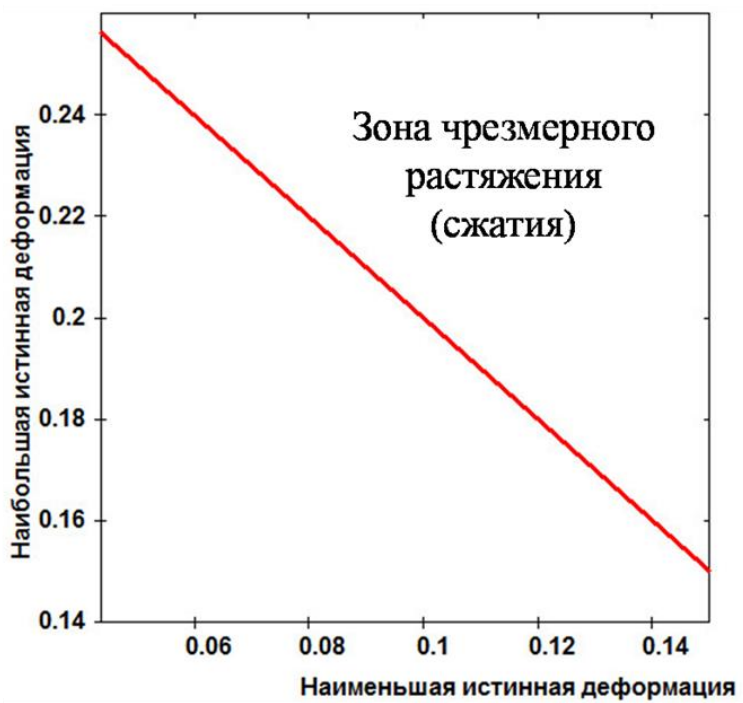

б)

Рисунок 1 - Зоны незначительной деформации (а) и чрезмерного растяжения/сжатия (б) материала при равноканальном угловом прессовании.

Незначительная деформация заготовки, соответствующая упругим деформациям, определена при истинной деформации в диапазоне $0.01-0.055$. Отрицательные значения истинной деформации характеризуют сжатие материала заготовки, положительные растяжение.
С течением времени и при постоянном давлении заготовка перемещается по угловому каналу матрицы. Создаются участки растяжения и сжатия материала. Значительное растяжение материала заготовки (пластическая деформация) наблюдается при величине истинной деформации от 0.15 и выше. 


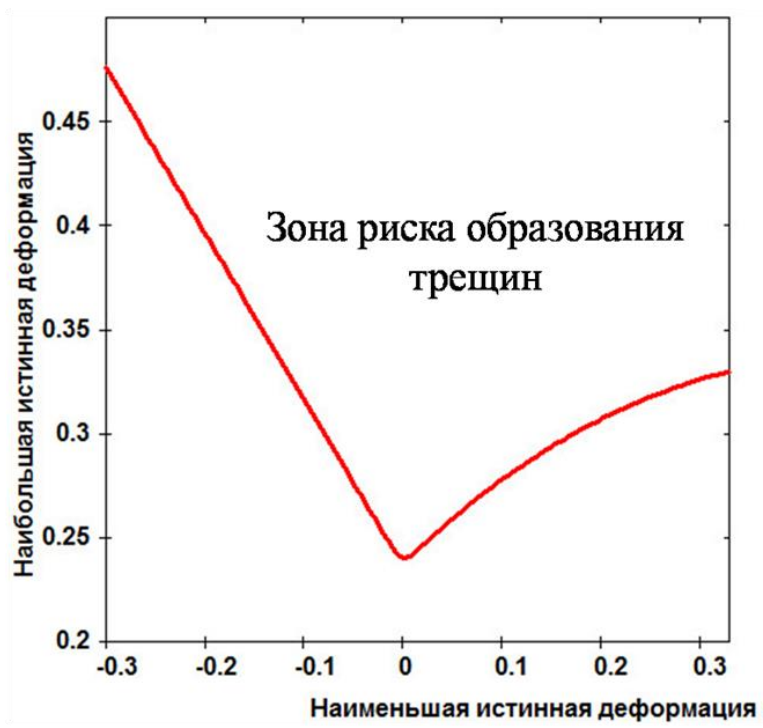

a)

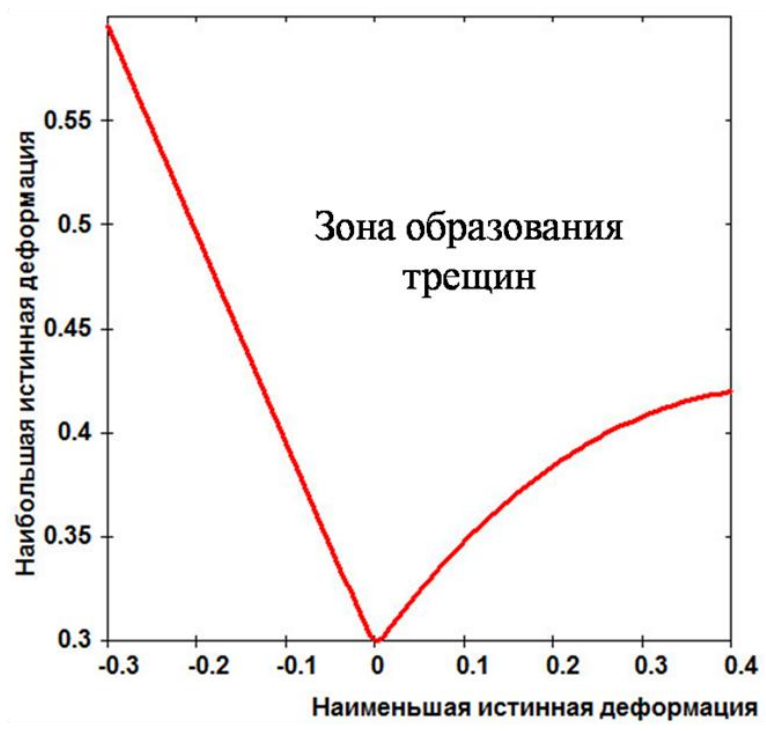

б)

Рисунок 2 - Зоны риска образования трещин (а) и образования трещин (б) в материале при равноканальном угловом прессовании.

Риск образования деформационных трещин возникает и при растяжении и при сжатии материала заготовки. При сжатии титановый сплав имеет большой запас прочности [7]. Величины истинной деформации материала при сжатии, в результате которой возможен риск образования трещин, составляют от 0.24 до 0.47 и выше, при растяжении - от 0.24 до 0.33. Зона образования трещин при РКУП формируется в условиях максимальных напряжений и деформаций материала (локальные участки изменение направления движения прессуемого материала под углом 90) сосредоточенных в большей степени у оси (внутренние трещины) и у поверхностного слоя (наружные трещины) заготовки.

Техническое продольное удлинение заготовки (среднее линейное удлинение или допустимое удлинение) - отношение изменения в длине деформируемой заготовки к ее первоначальной длине $[8,9]$. В табл. 1 представлены результаты расчета минимальных и максимальных величин технического продольного удлинения заготовки (в процентном выражении), которые характеризуют степень деформации материала на всем временном диапазоне процесса РКУП.

\section{Влияние величины технического продольного удлинения заготовки на степень деформации материала.}

\begin{tabular}{|c|c|c|}
\hline \multirow{2}{*}{ Зона деформации } & \multicolumn{2}{|c|}{ Техническое продольное удлинение заготовки, \% } \\
\cline { 2 - 3 } & Минимальное значение & Максимальное значение \\
\hline Незначительная деформация & 1.2 & 11.8 \\
\hline Чрезмерное растяжение & 16 & 77 \\
\hline Риск образования трещин & 28 & 94 \\
\hline Образование трещин & 34 & $<94$ \\
\hline
\end{tabular}

Деформация титанового сплава ВТ8 методом РКУП происходит в несколько этапов: упругая незначительная деформация материала в начальный момент приложения нагрузки на заготовку; чрезмерное растяжение материала заполняющего объем каналов матрицы (процесс продавливания материала из приемного канала в выходной); риск образования и образование трещин в материале при перемещении заготовки через место пересечения каналов матрицы. Минимальные значения истинной деформации и технического продольного удлинения заготовки, при котором происходит процесс трещинообразования, составляют 0.3 и $34 \%$ (треть от первоначальной длины заготовки) соответственно. 


\section{References:}

1. (2015) Treshchina. Available: https://ru.wikipedia.org/wiki/\%D2\%F0\%E5\%F 9\%E8\%ED\%E0 (Accessed: 08.06.2015).

2. (2015) Marochnik. Available: http://www.vimet.org/grade-list-131-c-Titan-splav-titana.html (Accessed: 08.06.2015).

3. (2015) Glavnye napryajeniya i glavnye ploshchadki. Available: http://sopromato.ru/napryazhennoe-sostoyaniev-tochke-uprugogo-tela/glavnie-ploshchadkinapryazheniya.html (Accessed: 08.06.2015).

4. Chemezov DA, Bayakina AV (2015) The intensity of stress \& strain of the model, which is made of titanium alloy $\mathrm{Ti}-6 \mathrm{Al}-4 \mathrm{~V}$, during equal channel angular pressing. ISJ Theoretical \& Applied Science 04 (24): 74-79. Soi: http://so-i.org/1.1/TAS*04(24)13 Doi: http://dx.doi.org/10.15863/TAS.2015.04.24.13
5. (2015) Istinnaya deformatsiya. Available: http://www.instron.ru/wa/glossary/TrueStrain.aspx (Accessed: 08.06.2015).

6. (2015) Teoriya OMD. Available: http://anybook.org/download/18120.html (Accessed: 08.06.2015).

7. (2015) Koeffitsient zapasa. Available: http://www.stresscalc.ru/help.php?num=2 (Accessed: 08.06.2015).

8. (2015) Engineering Strain Vs. True Strain. Available:

http://www.drd.com/techsupport/eng true_strai n.aspx (Accessed: 08.06.2015).

9. (2015) Tehnicheskoe prodolnoe udlinenie. Available: http://www.manualsteel.ru/term47848.html (Accessed: 